\title{
LIMITES CONSTITUCIONAIS DO PRINCÍPIO POLÍTICO DO BEM COMUM À REALIZAÇÃO DA IGUALDADE EM SOCIEDADES COMPLEXAS COMO A BRASILEIRA
}

\section{CONSTITUTIONAL LIMITS OF THE POLITICAL PRINCIPLE COMMON TO EQUALITY IN COMPLEX COMPANIES LIKE BRAZILIAN COMPANIES}

FREDERICO ANTONIO LIMA DE OLIVEIRA

Pós-doutor em Ciências Jurídico-Políticas da Faculdade de Direito da Universidade de Lisboa (FDUL). Doutor em Direito Constitucional (PUC/SP). Mestre em Direito Administrativo (UFPa).

\section{JEFERSON ANTONIO FERNANDES BACELAR}

Doutor em Direitos Fundamentais e Novos Direitos (UNESA/RJ). Mestre em Direito do Estado (UNAMA).

\section{RESUMO}

A ideia central deste estudo é traçar alguns possíveis parâmetros para a limitação do princípio político do bem comum numa sociedade complexa como a brasileira. Objetiva-se relacionar a busca da igualdade no estado brasileiro com os limites necessários à realização do bem comum, estabelecendo a prevalência de interesses em coalisão na esfera pública em análise, ante as nossas flagrantes iniciativas desestatizantes. Vale-se como referencial teórico de Jürgen Habermas quanto à esfera pública, revendo-se a literatura com a doutrina de John Finns. Tem-se uma pesquisa básica, exploratória, bibliográfica, com abordagem qualitativa e descritiva, a fim de se obter as conclusões necessárias. 
PALAVRAS-CHAVE: Bem Comum; Igualdade; Estado Social; Sociedade Complexa; Esfera Pública.

\begin{abstract}
The central idea of this study is to outline some possible parameters for limiting the political principle of the common good in a complex society such as Brazil. The objective is to relate the search for equality in the Brazilian state with the necessary limits to the realization of the common good, establishing the prevalence of interests in coalition in the public sphere under analysis, in view of our flagrant destatizing initiatives. It is worth as theoretical reference of Jürgen Habermas as far as the public sphere, being reviewed the literature with the doctrine of John Finns. We have a basic, exploratory, bibliographic research, with a qualitative and descriptive approach, in order to obtain the necessary conclusions.
\end{abstract}

KEYWORDS: Common Good; Equality; Social State; Complex Society; Public Sphere.

\title{
INTRODUÇÃO
}

A concepção de bem comum tem apontado desde as cidades gregas na filosofia política até a contemporaneidade, acerca da possibilidade de que certos bens, como segurança e justiça, só sejam possíveis através de suas realizações cidadãs na esfera pública. Nega-se com a concepção de bem comum a individualidade na sociedade, com indivíduos isolados, e sim, incorpora-se a participação cidadã e das relações sociais que se estabelecem. Preocupação recorrente hoje quanto à preservação do interesse privado e do bem particular. Desde Aristóteles, afirma-se que o homem é político e que somente pela participação política pode alcançar o bem comum de sua comunidade, seja por atividade política, jurídica ou mesmo bélica. A noção do bem comum foi também 
tratada pelos contratualistas modernos, e em Maquiavel, o bem comum seria alcançado por cidadãos virtuosos e dispostos. Os franceses do final do século XVIII, também trouxeram a concepção do bem comum com o bem estrar de todos e sua preservação. Capacitou-se, assim, o Estado a limitar o bem comum entre o interesse comum ou vontade geral e os interesses particulares como uma vontade geral particular, que justificaria a soberania do Estado e suas ações como uma comunidade moral, com várias implicações e dificuldades no mundo de hoje, face à alta complexidade e o alto grau de diferenciação das sociedades atuais.

Essa grande diferença de constituição social, e, portanto, de diversas realidades de vida dos grupos que compõe a sociedade brasileira, é sem dúvidas, fenômeno muito presente em países da conhecida periferia sociedade global ou com a menor quantidade de recursos econômicos. Dessa forma, traçados os primeiros parâmetros limitadores constitucionais da concepção de bem comum em nosso tema, rumamos para o problema apresentado, indagando neste estudo se após as limitações constitucionais propostas, acerca da possível realização do princípio da igualdade, numa sociedade complexa, plural e com diferentes ideias de justiça como é o caso brasileiro.

\section{CONSITUIÇÃO MORALMENTE REFLEXIVA}

A concepção de uma Constituição moralmente reflexiva apresenta uma sintonia bem visível entre os preceitos constitucionais e a evolução do tecido social, na medida em que se concebe a interpretação constitucional em se adequando os preceitos materiais às situações de fato, operando a ponderação de princípios pelo seu peso e prevalência. Desse entendimento, extrai-se, destarte as críticas que são usualmente postas ao dirigismo constitucional, destaca-se a relação do conceito de identidade constitucional e a intangibilidade das cláusulas pétreas que garantem a relação de prestação entre a Constituição e a sociedade, enquanto elemento fundamental da identidade constitucional. 
A impossibilidade de alteração do conteúdo das cláusulas pétreas em contra partida à abertura conferida às normas constitucionais como meio de integração do sistema constitucional é bem enfrentada por Canotilho, quando reconhece a intangibilidade ou imutabilidade dos preceitos fundamentais da Constituição, como uma conquista histórica da sociedade, prevendo duas possibiidades mais específicas, sendo elas: a) a petricidade das cláusulas que garantem o regime material e não os preceitos constitucionais concretos; b) as cláusulas pétreas materiais e expressas, que detenham correspondência com o texto da Constituição, dizendo respeito à própria essência do texto constitucional em foco.

Essa fórmula encontrada por Canotilho, ao passo em que admite a possibilidade de desenvolvimento constitucional de fórmulas emancipatórias no rumo de uma democracia socialista, a exemplo do que fora feito na Constituição portuguesa, com o exercício democrático do poder pelas classes trabalhadoras e a garantia do pacífico processo revolucionário. No pertinente ao grau de abertura das normas constitucionais, e, da mesma forma, a garantia pétrea da identidade constitucional no conteúdo material das normas consideradas fundamentais, observa-se, sem maior embaraço, dois pontos importantes, nos parecem terem sido respeitados na tese de Canotilho, quais sejam: a) a estabilidade constitucional, através da garantia pétrea do conteúdo material da relação Constituição/Estado (identidade constitucional); e, ao seu turno, b) o desenvolvimento constitucional, fundamentado numa nova compreensão dos princípios em consonância com os novos problemas sociais (CANOTILHO, 1998, p.1-10).

$\mathrm{Na}$ atualidade, nota-se, no mesmo passo da visível dificuldade em se assegurar a eficácia social das normas de caráter programático, a polêmica gerada sobre os limites de atuação positiva dos poderes do Estado, e, em particular, do Poder Judiciário. Os Tribunais passsam a ter uma função de grande importância, não só preenchendo as omissões do Poder Legislativo, mas, sobretudo, como entendemos neste estudo, implementando valores democráticos fundamentais (implícitos ou explícitos), por meio das chamadas normas constitucionais de conteúdo aberto. Assim, nos parece cabível e justa a sentença proferida por Oscar Vieira Vilhena: 
(...) este caráter aberto e dirigente de diversas Constituições é bastante acentuado na Constituição brasileira e, para os defensores de um Estado mínimo, sinal de impraticabilidade ou inviabilidade destes textos. Esta posição, no entanto, é, sobretudo, uma posição conservadora. De quem não está preocupado com os problemas agudos de justiça social, como os que permeiam a nossa sociedade (...) (STF, 2012, p.39).

Tentamos sintetizar sem escalas, a adequação dos preceitos de Canotilho à realidade brasileira, profundamente influenciada pela doutrina constitucional portuguesa, a quando da promulgação da Constituição de 1988. Sem o total atrelamento do constitucionalismo moderno, a doutrina do constitucionalismo moralmente reflexivo abre espaço para a inserção de novos direitos emergentes como os direitos sociais e de novos sujeitos de direito constitucional, propiciando, proporcionalmente, maior eficácia e legitimidade e menor insegurança jurídica ao ordenamento jurídico.

A lógica desenvolvida no constitucionalismo reflexivo nos leva a conceber, a nossa ótica, acertadamente, que a potência constitucional, em estado de latência constante (poder constituinte), necessita de uma condição emancipatória que Ihe é intrínseca e que justifica a sua existência no texto constitucional. Ora, se assim é verdade, também o é o fato de que as garantias materialmente pétreas da Constituição devem ser observadas sob o ponto de vista material de seu conteúdo, e não formalmente consideradas para os efeitos da intangibilidade ou imutabilidade. Por outro lado, a mensagem constitucional emancipatória, que dá lastro para os processos de mutação constitucional (BOULOS, 2002) não se mostra compatível com o "engessamento" de imposições constitucionais que garantam políticas públicas sociais, econômicas e culturais, ou ainda, que tornem intangíveis direitos de conteúdo meramente formal no texto constitucional.

O contexto acima, mais especificamente na obra "The Living Constitution", David Strauss ${ }^{1}$ aponta a Constituição dos Estados Unidos foi mantida atual desde 1787, ainda ditando as regras da sociedade americana, por força da clara compreensão dos significados de suas palavras, sedimentados em tradições pelos juízes, de forma muito próxima ao que acontece no sistema da common law, e, 
sobretudo, nos casos em que a Constituição não oferece uma solução única, devendo se ver qual a saída para o caso, com o uso da razão e dos argumentos sobre justiça e a melhores políticas.

$O$ apelo substancialista do contexto constitucional que tomamos para esta análise, funda-se, em uma constitucionalidade advinda da teoria de estado político e, assim como se tem mais à miúde, o papel da Constituição como um mecanismo que detém o Estado numa dimensão social, com uma realidade social, o que nos mostra a separação possível nos níveis do ordenamento jurídico ordinário e a ordem administrativa e a ordem constitucional, o que afastou na obra de Rudolf Smend que, em nível da Constituição a postura estática que disse Smend adotar o positivismo e, nesse sentido, neokantiano, onde o estatismo kelseniano haveria de ser superado pela integração dos valores obtidos com a Constituição².

Doutra parte, semelhante o arremate teórico que se dá com a concepção do teórico alemão Hermann Heller que classificou a sociedade como uma comunidade de vontade e valores, sendo o Estado solidário com as articulações sociais que constituem o poder ${ }^{3}$, daí porque a estrutura do modelo de Estado para análise, que foi o Estado Liberal, onde a estrutura burguesa dos fatores reais de poder como em Ferdinand Lassalle ${ }^{4}$, existentes em toda a sociedade, através daqueles que governam, exercem inlfuência efetiva, e nem tão democrática como se desejava, para o fecho necessário de legitimidade e de aceitação que, nos padrões burgueses e individuais pregados nos esferas públicas, que mais à frente veremos em Habermas, substancialmente, nos mostram a igualdade como valor mais caro a ser obtido, a fim de com esse valor obter a sociedade e suas diversas esferas públicas o bem comum desejável não só pela sociedade como pelo próprio Estado, que, existencialmente, busca realizá-lo como princípio político fundamental.

$\mathrm{O}$ traçado que se observou junto à primeira fase do positivismo jurídico, com as divergências e ponderações do constitucionalismo substancialista, trouxe-nos à linha extra-jurídica que nos mostrou um padrão moral, que, no sentir de uma

${ }^{2}$ Cf. SMEND, 1985. Cf. 1988.

${ }^{3}$ Cf. HELLER, 1968.

${ }^{4}$ Cf. LASALE, 2019. 
sociedade de intérpretes da Constituição ${ }^{5}$ nos remete a uma maior igualdade no texto constitucional, ora constituído numa acepção substantiva e política da vontade maior do Estado que confere a buscada integridade que as ordens jurídica e constitucional não prescindem, e, dessa forma, leva-nos ao fio condutor da igualdade entre os diversos grupos sociais, plurais, que refletem moralmente suas necessidades no texto constitucional a ser analisado.

As "linhas de força" do constitucionalismo moralmente reflexivo pautam-se, em síntese, em três linhas de entendimento. A necessidade do constitucionalismo contemporâneo de oferecer exigências constitucionais mínimas à cidadania - direitos fundamentais - perfazendo a dimensão básica da legitimidade moral e material. O estabelecimento de pressupostos mínimos de justiça em relação às estruturas básicas particulares, respeitando as desigualdades, mas, ao mesmo tempo, promovendo uma simetria de oportunidades, o que, se aproxima, sobremaneira, das novas concepções de igualdade complexa (Habermas), igualdade de oportunidades (Dallari) e igualdade de tratamento (Dworkin). Por fim, a mudança de foco proposta por Canotilho, no que se refere à passagem do constitucionalismo moderno, onde a Constituição funcionava como uma ordem política superior, orgânica e planejada, para um constitucionalismo reflexivo, onde a Constituição mantém-se como ordem política e planejada, mas, sobretudo, estabelece, não apenas diretivas dirigentes impostas ao cumprimento de forma autoritária, mas, instrumentos que reformam a noção de responsabilidade civil, estabelecendo um novo pacto de responsabilidade constitucional, que reforça o cooperativismo e pluralismo políticos, conforme se assentam assegurados, inclusive, como já assaz mencionado, como princípios fundantes do Estado democrático brasileiro (art. $1^{\circ}$. e $3^{\circ}$. da CRB). 


\section{LIMITES CONSTITUCIONAIS DO BEM COMUM NA ESFERA PÚBLICA HABERMASIANA}

A saber, sobre as linhas e força a serem observadas em face do chamado constitucionalismo moralmente reflexivo, tem-se que a estrutura básica de realização de tal consitucionalismo, nos propõe, como dito acima três linhas de entendimento, mais específicamente: a) a legitimidade moral e matrial dos chamdos direitos fundamentais; b) o estabelecimento de pressupostos mínimos com relação a idéia de justiça, e, por fim; c) a transição do constitucionalismo moderno para um período onde o constitucionalismo é moralmente reflexivo, ou seja, construído a partir do cooperativismo e do pluralismo político.

O tripé básico que anunciamos acima, remete-nos, a saber, quanto a necessidade de serem estabelecido limites racionais para a delimitação das necessidades provinddas da sociedade, que, no campo sociológico habermasiano vêm a ser desta feita entendidas para nossa análise como partes da esfera pública do Estado, e onde, os princípios e necessidades em construção irão se constitucionalizar, o que, conceitualmente, difere da base formal e histórica do movimento chamado de constitucionalismo.

O sentido mais contemporâneo de esfera pública do Estado, como bem analisou o conceito o próprio Habermas, surge como elemento histórico das sociedades burguesas, e por tanto, individualistas, com sujeitos capazes de expressarem opiniões sobre assuntos de interesse geral, através do que se formulou como opinão pública que através de um julgamento histórico seria capaz de controlar o poder político por meio da publicização das ações políticas institucionais. Esse mecanismo socio-político racionalizará as ações mais importantes e necessárias na sociedade, elegendo, consequentemente, o primado do bem público a ser prevalentemente assegurado (HABERMANS, 2003, p.5-20).

Senão vejamos que, o sentido dado por Habermas à esfera pública se posta na realidade do séc XVIII, onde a propriedade e individualidade burguesas ressaltavam um sentido de igualdde e interesse comum emergente de relações eminentemente privadas, porém, o fator de conexão entre os interesses dessas 
pessoas estaria gravado na propriedade privada, composta de vários dos direitos personalissimos existentes, o que se entendeu como autonomia privada (familia, propriedade, partidos e outros), e, ao seu turno, a esfera pública como dito anteriormente, teria seu recorte de ação relacionado ao exercício cítico da opinião pública e sua ação comunicativa.

A racionalidade da ação produto da comunicação tem variações de qualidade na opinião pública gerada, ou seja, as pessoas privadas buscam opiniões públicas para seus interesses que são sociais ou coletivizaveis (o princípio político do bem comum). Desa forma, parece-nos que em Habermas, o que se lê é que as condições de comunicação se diferenciam na passagem de um tema privado para a esfera pública, como já dito, pela capacidade de se articular o intesse existente como interesse social, ou geral, tudo em busca de uma linha de igualdade na busca do bem comum democraticamente definido, sendo em qualquer caso definidos os limites dos direitos fundamentais envolvidos que garantam as liberdades públicas envolvidas, pois, somente com uma esfera privada livre é que a pública poderá existir.

Habermas aponta a existência da desigualdade nas posições dentro da esfera pública moderna, e, revendo seus conceitos, reconhece a existência de vários grupos de interesses (grupos sociais) ou de pressão que terão, porventura, acesso privilegiado às informações existentes. Dese forma, adimitindo a existência de mais de uma esfera pública, portanto, também adimite um maior grau de diferenciação na sociedade, o que só poderá ocorrer com a redução das desigualdades geradas, e, portanto, da complexidade existente. Essa perspectiva, pretende ao fim e ao cabo, alterar o debate democraticamente produzido para selecionar as esolhas legais do Estado político, e por ele regradas, a fim de que alcancem o bem comum almejado pela maioria que participar mais participar dos debates institucionais (HABERMANS, 2003, p.25) ${ }^{6}$.

Dessa forma, as escolhas polítcas, democratica e racionalmente produzidas em lei, haverão de estar consignadas e ligitimadas no aparelho normativo do Estado, limitando constitucionalmente o exercício da força estatado, e criando as condições

${ }^{6}$ Cf. HABERMANS, 2003b. 
políticas aceitáveis e, portanto, legítimas para a consecução do bem comum (como bem de todos) a ser realizado com desiderato final do Estado político.

Sem que necessitemos invadir a seara do debate entre a esfera pública e os espaços públicos democrativamente produzidos, urge que saibamos que em sociedades com alto grau de pluralismo político e jurídico como a brasileira, as realidades sociais, levam-nos a uma importante grade de escolhas públicas a serem feitas pelo Estado, e, consequentemente, a um sensível aumento na complexidade (CAMPILONGO, 2000) e no risco de tais escolhas, o que, por muitas vezes acaba por levar-nos à injustiça ou ineficácia de seus atos legais.

As limitações constitucionais impostas na compreensão dos princípios e necessidades que orbitam como vimos em várias esferas públicas que se comunicam, interagem e participam na sociedade democrática, segundo a visão habermasiana, sem se olvidar da impescindível integridade do sistema jurídico, como já dito, através da igualdade entre as autonomias privadas.

\section{A TEORIA DE JOHN FINNIS PARA OS LIMITES RACIONAIS QUE PODEM DETERMINAR O BEM COMUM NA ESFERA PÚBLICA BRASILEIRA}

Do positivismo jurídico e suas dimensões histórica, política e jurídica, incluídas então tanto as noções de ordenamento como de sistema jurídico, a fim de se extrair o debate que em parte já perpassamos, anteriormente, entre aqueles que entenderam a constituição como um fenômeno político, estando inserida num contexto substancialista e, aqueles que se inseriram no primeiro conceito constitucional clássico, onde a constituição seria um instrumento reparado e mediador da força do Estado através da lei. Esse debate se apresentou nos primórdios do que soubemos tratar e ser afastado do contexto histórico jurídico, o fenômeno epistemológico tido como naturalismo, que, distanciando-se das referências metafísicas, nos remete hoje, mais uma vez, por via da necessária inserção da razão do imperativo de garantias do indivíduo contra o Estado. 
Dessa forma, buscam-se alternativas técnicas e práticas para as omissões do positivismo clássico, com as novas discussões oportunizadas pelo jusnaturalismo e pelo chamado neopositivismo. Eis que nos parece propício o pensamento do John M. Finnis que racionalmente, pretende equiparar, com seu juspositivismo, as concepções de lei e direito, a fim de nos fornecer alguns interessantes elementos aptos a limitar constitucionalmente o bem comum das esferas públicas brasileiras, como se pretende observar neste estudo.

Em que pese a estrutura do direito avaliar com cuidado os elementos metajurídicos como política e moral, valendo-se, para tanto do uso da razão dos operadores que aplicam a lei para se compreender que, mesmo sob a égide de um julgamento neutro do Estado, o advento dos direitos humanos nos traz a concepção de que nem sempre os fundamentos da regra conformam-se com a vontade popular, e assim, da mesma forma, nem sempre o positivismo traduz com eficácia a vontade inserta na norma sobre concepções como as de bem-estar social e boa qualidade de vida como princípios político-constitucionais setoriais na esfera pública ambiental brasileira, ou, como em nossa análise, aquelas ligadas ao princípio político constitucional do bem comum, próprias das demais esferas públicas e privadas desta mesma sociedade brasileira? .

Vê-se em Bobbio (1995b, p.5-40) $)^{8}$ que o uso da força pelo Estado não se mostra atrelado a um padrão moral ou a um ideal de justiça (WALZER, 1999, p.21$45)$, indo na contramão da proposta dos direitos humanos que defendem os direitos individuais desde sua primeira dimensão, independente do Poder Legislativo. Essa concepção positivista de integridade e solução dos casos pelo caminho único da regra jurídica torna difíceis os melhores resultados das decisões dos Estados.

A concepção de Finnis nos parece bem alinhar algumas respostas que se prestam a estabelecer um recorte teórico importante para estabelecermos os possíveis limites constitucionais aplicáveis ao bem comum das esferas públicas da sociedade complexa brasileira. Dois pontos importantes para uma abordagem mais pragmática se fazem necessários na leitura de Finnis, um deles se dá com a

7 Cf. FINNIS, 1998; 1983.

${ }^{8}$ Cf. BOBBIO, 1995b. p. 10-20; CARRIÓ, 1994. p. 5-10. 
igualdade dada pelo direito à lei, afastando a necessidade de conexão do direito com a moral, e, encaminhando a proteção dos direitos humanos com a concordância do poder público, e, o outro é que os bens humanos básicos por ele definidos como a vida, e outros essenciais, estariam além das questões políticas, jurídicas ou morais, e, pelo que percebemos, a partir de Tomáz de Aquino ${ }^{9}$, vale-se daquilo que chama da racionalidade ou de razão prática nas ações humanas, onde, as motivações estão coectadas à inteligência da natureza humana pelo seu conhecimento prático ou moral, no sentido de que o interesse humano se dirige para o bem. Esse seria o uso racional da natureza humana, o que, por óbvio, possibilitaria com o entendimento do sentido impresso nos valores comuns e maiores existentes em cada esfera pública da sociedade, nas possíveis limitações e definições constitucionais do princípio político do bem comum, a partir de sua compreensão nas esferas públicas da complexa sociedade brasileira ${ }^{10}$.

\section{CONCLUSÃO}

Como considerações finais deste estudo, à título de possíveis respostas ao objeto desta análise, temos que:

a) o sentido de esfera pública do Estado, segmentado em várias possíveis esferas, têm como elemento histórico, burguês e individualista, diz respeito a expressão de opiniões sobre assuntos de interesse geral, através do que se formulou como opinão pública que, por último, mostra-se capaz de controlar o poder político por meio da publicização das ações institucionais;

b) o mecanismo sócio-político da esfera-pública racionalizará as ações mais importantes e necessárias na sociedade, ou, que consagram direitos fundamentais, elegendo, consequentemente, o primado do bem público a ser prevalentemente priorizado e efetivado;

${ }^{9}$ Cf. AQUINO, 2015.

${ }^{10} \mathrm{Cf}$. FINNIS, 2000. 1991. 2011. 
c) o alto grau de pluralismo político e jurídico da sociedade brasileira, levam-nos a um fatal aumento da complexidade e risco existentes nas escolhas do Estado, o que, por muitas vezes acaba por nos levar à injustiças ou ineficácias de seus atos legais;

d) as limitações constitucionais impostas na compreensão dos princípios e necessidades que orbitam em várias esferas públicas brasileiras necessitam, imperiosamente, em que sejam preservadas as autonomias privadas esistentes, a fim de ser produzida a necessária igualdade e, por conseguinte, preservada a integridade do sistema;

e) a par do direito muito avaliar elementos metajurídicos como política e moral, vale-se, em todo o caso, do uso da razão para se compreender um julgamento neutro do Estado, norteado pelos direitos humanos, e, por esse mesmo prisma, conformando-se com a vontade popular, nem sempre traduzida no positivismo, com eficácia, tal como afeta as concepções de bem-estar social e boa qualidade de vida como princípios políticoconstitucionais setoriais nas esferas públicas brasileiras;

f) em Finnis vê-se que a igualdade é dada ao direito com a lei (law para os norte-americanos), invés de uma necessária conexão com a moral, e, assim, propiciando uma concordância do poder público com a defesa e proteção dos direitos humanos;

g) a racionalidade ou de razão prática nas ações humanas, onde as motivações estão conectadas à inteligência da natureza humana pelo seu conhecimento prático ou moral, no sentido de que o interesse humano se dirige para o bem, e dessa forma, virá a possivelmente limitar constitucionalmente, por meio das construções hermenêuticas, os bens humanos básicos ou valores humanos que coalidem, porém, em constantes choques ou conflitos mesmo que parciais. 


\section{REFERÊNCIAS}

AQUINO, Tomás de. Suma Teológica. Tradução Carlos Josaphat Pinto de Oliveira et al. v. 106 4; 6. 3a ed. São Paulo: Edições Loyola, 2015.

BARROSO, Luís Roberto. Da falta de efetividade à judicialização excessiva: direito à saúde, fornecimento gratuito de medicamentos e parâmetros para a atuação judicial. Revista da Procuradoria Geral do Estado do Rio Grande do Sul. vol. 9, n. 24. Porto Alegre: PGE, 1979. p. 89-114.

A dignidade da pessoa humana no direito constitucional contemporâneo: a construção de um conceito jurídico à luz da jurisprudência mundial. Tradução: Humberto Laport de Mello. Belo Horizonte: Fórum, 2013.

BOBBIO, Norberto. O positivismo jurídico: lições de filosofia do direito. São Paulo: Ícone, 1995a. Brasília, 1995b.

Teoria do ordenamento jurídico. 6.ed. Brasília: Editora Universidade de

BOULOS, Christianne. Coalisão de direitos fundamentais. 2002. Dissertação (Mestrado em Direito) - Curso de Pós-Graduação em Direito, Universidade do Estado de São Paulo, São Paulo, 2002.

BUCCI, Maria Paula Dallari Bucci. Direito administrativo e políticas públicas. São Paulo:Saraiva. 2002.

Fundamentos para uma teoria jurídica das políticas públicas. São Paulo: Saraiva. 2013.

CAMPILONGO, Celso Fernandes. O direito na sociedade complexa. São Paulo: Max Limonad, 2000.

CANOTILHO, J.J. Gomes. Constituição da República Portuguesa - lei do tribunal

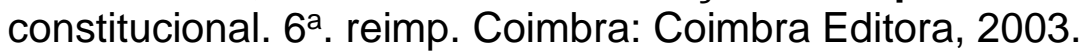

. Direito na sociedade complexa. São Paulo: Max Limonad, 2000.

. Direito Constitucional. 2ª ed. Coimbra: Livraria Almedina, 1998.

. Constituição Dirigente e Vinculação do Legislador. Coimbra: Almedina,

1998.

. Direito Constitucional e Teoria da Constituição. Coimbra: Almedina, 1998. 
. Direito e democracia. São Paulo: Max Limonad, 1997.

CANOTILHO, Joaquim José Gomes e MOREIRA, Vital. Fundamentos da constituição. Coimbra: Coimbra, 1991.

CASTILHO, Ricardo. Justiça Social e Distributiva desafios para concretizar direitos sociais. São Paulo: Saraiva, 2009.

DE GIORGI, Raffaele. Direito, democracia e risco: vínculos com o futuro. Porto Alegre: SAFE, 1998.

DOBROWOLSKI, Samantha Chantal. A Justificação do Direito e sua Adequação Social uma abordagem a partir da teoria de AULIS AARNIO. Porto Alegre: Livraria do Advogado Editora, 2012.

FINNIS, John. Aquinas: moral, political and legal theory. Oxford: Oxford University Press, 1998.

1983.

Fundamentals of ethics. Washington: Georgetown University Press,

Ley natural y derechos naturales. Tradução Cristóbal Orrego. Buenos Aires: Abeledo-Perrot, 2000.

University Press, 1991.

Moral absolutes: Tradition, revision and truth. Washington: The Catholic

Natural law and natural rights. 2nd ed. New York: Oxford University Press, 2011.

FISS, Owen. El derecho como razón pública. Trducción de Esteban Restrepo Saldarriaga.Madrid:Marcial Pons, 2007.

GARGARELLA, Roberto. As Teorias da Justiça depois de Rawls um breve manual de filosofia política. Tradução Alonso Reis Freire, Revisão da tradução Elza Maria Gasparotto, Revisão técnica Eduardo Appio. São Paulo: WMF Martins Fontes, 2008.

HÄBERLE, Peter. Hermenêutica constitucional: a sociedade aberta dos intérpretes da Constituição: contribuição para a interpretação pluralista e "procedimental" da Constituição. Trad. Gilmar Ferreira Mendes. Porto Alegre: Fabris, 1997.

HABERMAS, Jürgen. Mudança estrutural da esfera pública: investigações quanto a uma categoria da sociedade burguesa. Rio de janeiro: Tempo Brasileiro, 2003a. 
. Direito e democracia: entre facticidade e validade. Vol II. $2^{\text {a }}$ ed. Rio de Janeiro: Tempo Brasileiro, 2003b.

HELLER, Hermann. Teoria do Estado. Trad. Lycurgo Gomes da Motta, São Paulo: Mestre Jou, 1968.

Teoría del Estado: política y derecho. Traducción de Luis Tobio. México: Fondo de Cultura Económica, 2002.

LASALE, Ferdinand. O que é a Constituição. São Paulo: Edijur, 2019.

OLIVEIRA, E. S. Bem comum, razoabilidade prática e direito: A fundamentação do conceito de bem comum na obra de John M. Finnis. 2002. 144 f. Dissertação (Mestrado em Direito) - Faculdade de Direito da Universidade Federal do Rio Grande do Sul, Porto Alegre, 2002.

PINTO, Eduardo Vera-Cruz. Lições de História do Direito Romano I. Síntese geral. 2ª reimpressão. AAFDL Editora, 2018.

RAZ, Joseph; ALEXY, Robert; BULYGIN, Eugenio. Uma discussão sobre a teoria do direito. Tradução: Sheila Stolz. São Paulo: Marcial Pons, 2013.

ROSA, Eliana de. Introducción a la teoría jurídica de John Finnis. Revista RyD República y Derecho, Mendoza, Argentina, v. 1, p. 1-22, 2016.

SANTOS, André Leonardo Copeti; HAHN Noli Bernardo; ANGELIN; Rosânngela (Coord.). Policromia da Diferença: inovações sobre pluralismo, direito e interculturalidade. Lisboa: Juruá, 2015.

SMEND, Rudolf. Constitución y Derecho Constitucional (1928). In: Constitución y Derecho Constitucional. Trad. José Maria Beneyto Pérez. Madrid: Centro de Estudios Constitucionales, 1985.

Giuffré, 1988.

Constituzione e diritto consituzionale. Trad. F. Fiore, J. Luther. Milano:

STRAUSS, David A. The Living Constitution. New York: Oxford University Press, 2010.

STRECK, Lenio Luiz; ROCHA, Leonel Severo; ENGELMANN, Wilson (Orgs.). Constituição, Sistemas Sociais e Hermenêutica: anuário do programa de PósGraduação em Direito da UNISINOS. Porto Alegre: Livraria do Advogado Editora; São Leopoldo: UNISINOS, 2014.

SUNSTEIN, Cass R. Antonin Scalia, Living Constitutionalist. Harvard Law Review, Forthcoming; Harvard Public Law Working Paper, n. 15-16, 2016. 
VIEIRA, Oscar Vilhena. Supremo Tribunal Federal - jurisprudência política. $2^{\mathrm{a}}$. ed. São Paulo: Malheiros Editores, 2002.

A Constituição e sua reserva de justiça - um ensaio sobre os limites materiais ao poder de reforma. São Paulo: Malheiros Editores, 1999.

WALZER, Michael. As esferas da justiça em defesa do pluralismo e da igualdade. Tradução: Nuno Valadas. Lisboa: Editorial Presença, 1999. 